\title{
Urgences
}

\section{Nicolas-du-grabuge-au-cœur (dessins de Nicolas Dupuis)}

\section{Gilbert Dupuis}

Numéro 6, 4e trimestre 1982

URI : https://id.erudit.org/iderudit/025091ar

DOI : https://doi.org/10.7202/025091ar

Aller au sommaire du numéro

Éditeur(s)

Urgences

ISSN

0226-9554 (imprimé)

1927-3924 (numérique)

Découvrir la revue

Citer ce document

Dupuis, G. (1982). Nicolas-du-grabuge-au-cœur (dessins de Nicolas Dupuis).

Urgences, (6), 37-52. https://doi.org/10.7202/025091ar d'utilisation que vous pouvez consulter en ligne.

https://apropos.erudit.org/fr/usagers/politique-dutilisation/ 


\title{
GILBERT DUPUIS
}

\section{Nicolas-du-grabuge-au-coeur}

\author{
(dessins de Nicolas Dupuis)
}

“.. communiquer le frémissement imperceptib/e de cette vie nouvelle qui naît dans des mots sim ples et si bien disposés dans l'espace du texte qu'on ne saurait y intervenir sans détruire l'instant de bonheur fugitif."

Michelle Dubois 
1.

presque trois ans il sait sourire en mangeant des raisins

bleus et verts dans l'eau fraîche ce dimanche à peine entamé par le petit soleil des fenétres

mais encore

l'intensité paternelle biaise l'incident et tremble l'image d'abord ordinaire

trois années déjà

qu'il s'inquiète

dans les yeux de son fils 
2.

il dessine des chèvres en flammes et d'immenses vautours charbons les fixe aux murs de la cuisine va se laver les mains

puis revient dévorer son fromage

serait-il euphorique

Nicolas ce matin 


\section{3.}

I'enfant se pique au jeu

dans la neige anniversaire

sans rougir trop des froidures

sous sa casquette de fiction

il s'amuse tant des toboggans obliques des fortins de glace des mottes à deux boules comme heureux de changer le paysage qu'il en oublie l'histoire du clown qui tenait toutes les ficelles du monde et qui riait dans ses nuages 


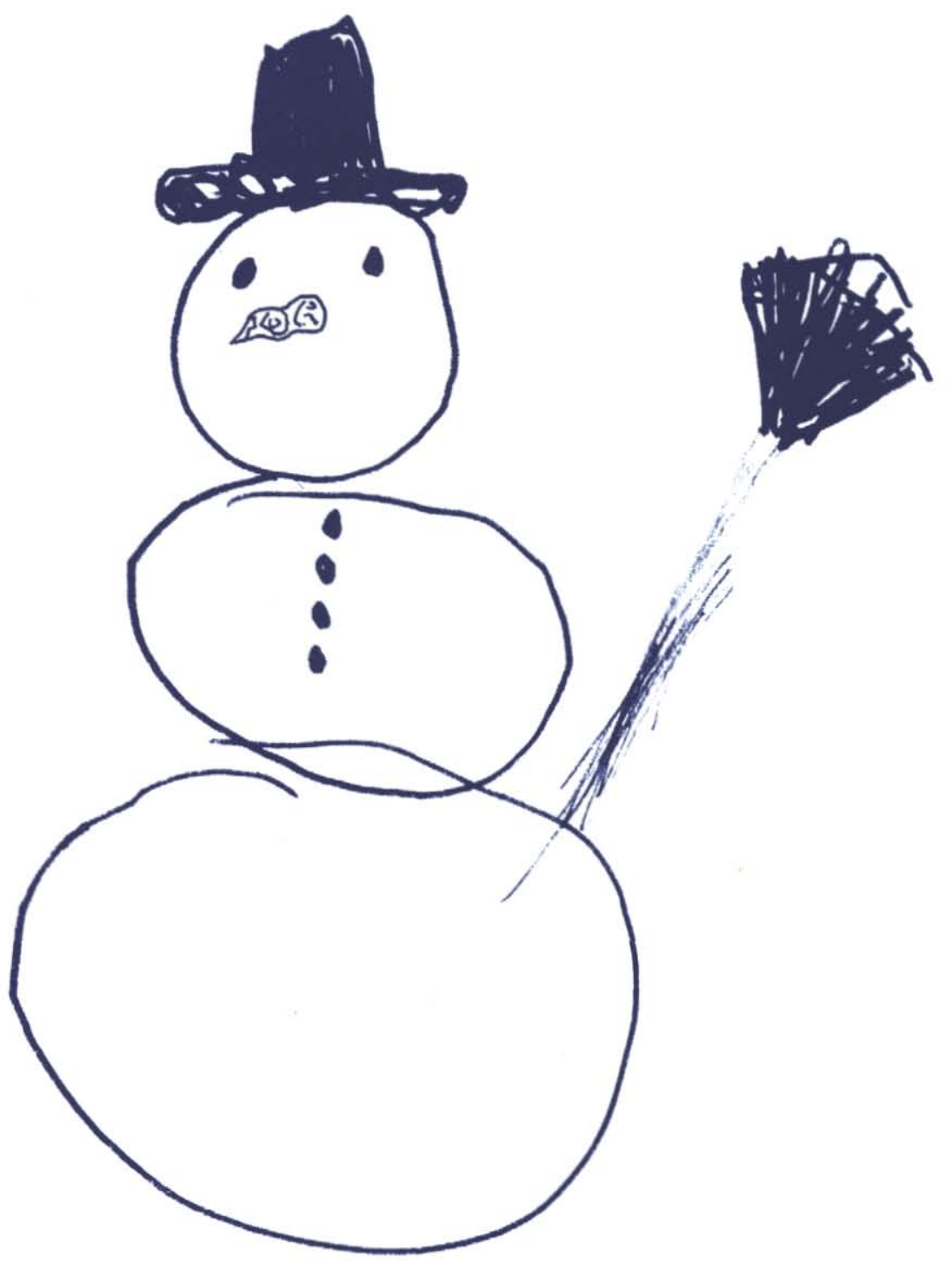


4.

pour une berceuse dans son lit

il babille les mains au plafond

si haut si blanc si haut le plafond que l'écho de ma complainte

lui parvient trente ans plus tard et qu'il s'y reconnaît à peine pour cause de magie chagrine dans sa propre musique 
5.

derrière ses paupières de soie

I'enfance bouge dans un tissu difficile

I'enfance s'étonne de comprendre

que toute la vie reste à colorier

il frissonne se cabre ne rompt point comme un petit cheval urbain

Nicolas s'initie aux tensions du jour

sa tête lui pèse

qu'une larme perlée allège

il rêve qu'il dort

sans couverture bleue 
6.

il joue à boire et goûter pleure et pisse espiègle s'amuse à m'aimer à rire à s'éteindre à poings fermés

(la nuit l'horloge complote des automnes)

mais toujours mon fils ressuscite pour réviser l'innocence originelle gesticuler des gamineries capitales chambouler joyeux mes scénarios pour (bien) faire l'enfant

avant d'aller vers le sommeil comme si de rien n'était 
7.

les yeux passés la somnolence Nicolas bouge tout doux ses doigts quand les miens caressent sa cuirette chevelue autour de minuit toujours

il serre de près si bien ses songes et sommeille tranquille tellement sur la scène de mes gestes rituels que mes yeux se dissolvent salins sur nous

il $y$ a trente ans mon père tes mains à toi ne savaient-elles que bûcher? 
8.

tu parles tu parles

mais si mystère la parole

si difficile la clarté

que j'écoute jusqu'au trouble

tes histoires en zigzag

le fouillis de tes enquêtes

longtemps longtemps pour quelques secrets

remontés à ras le bord des yeux

mais ton rire calorifère

fera fondre mes gros sabots

et j'avancerai dans ta maison

me prendre pour un enfant

en plein jour du coeur

et me refaire une oreille

tu parles 


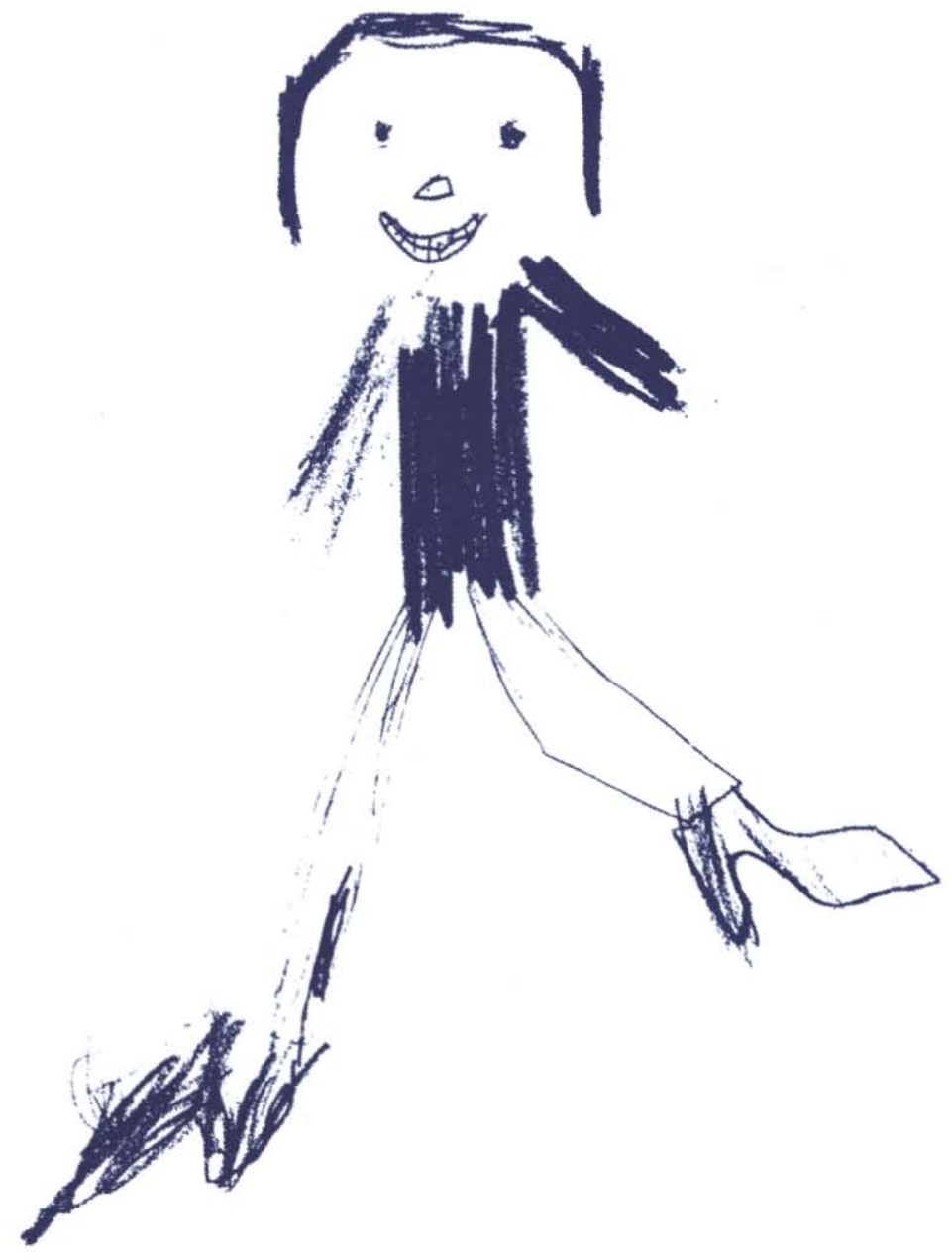


9.

tout fin seul dans la neige

il dort sans mitaines un sourire de son âge

sur ses lèvres bleues

azur éternité 
10.

il tourne autour du bonhomme le souffle blanc dans l'air et la fleur de peau fragile encore pour tant d'hivers à dégourdir

il sent son énergie brouillonne il s'agite roule s'exclame il glisse s'envole m'étourdit et $m^{\prime}$ invente des vertiges au plexus

je le trouve dans tous les sens Nicolas-du-grabuge-au-coeur qui tourne sur lui-même pour me voir et s'apprendre 
11.

t'entendre rire par la fenêtre

mes semelles dans le travail du jardin

ce printemps plein d'oiseaux jaunes

mon fils de jeunesse en éclats

$t^{\prime}$ entendre rire

me plante un violon dans le coeur

me fait tituber tomber en enfance

me remet au monde du soleil

et quand tes signaux me touchent

(mon dieu quand tes mains me reconnaissent)

mes yeux s'emplissent de petits bateaux

et des bonheurs me trouvent

parti semer des oranges

dans ma tête

pour deux 


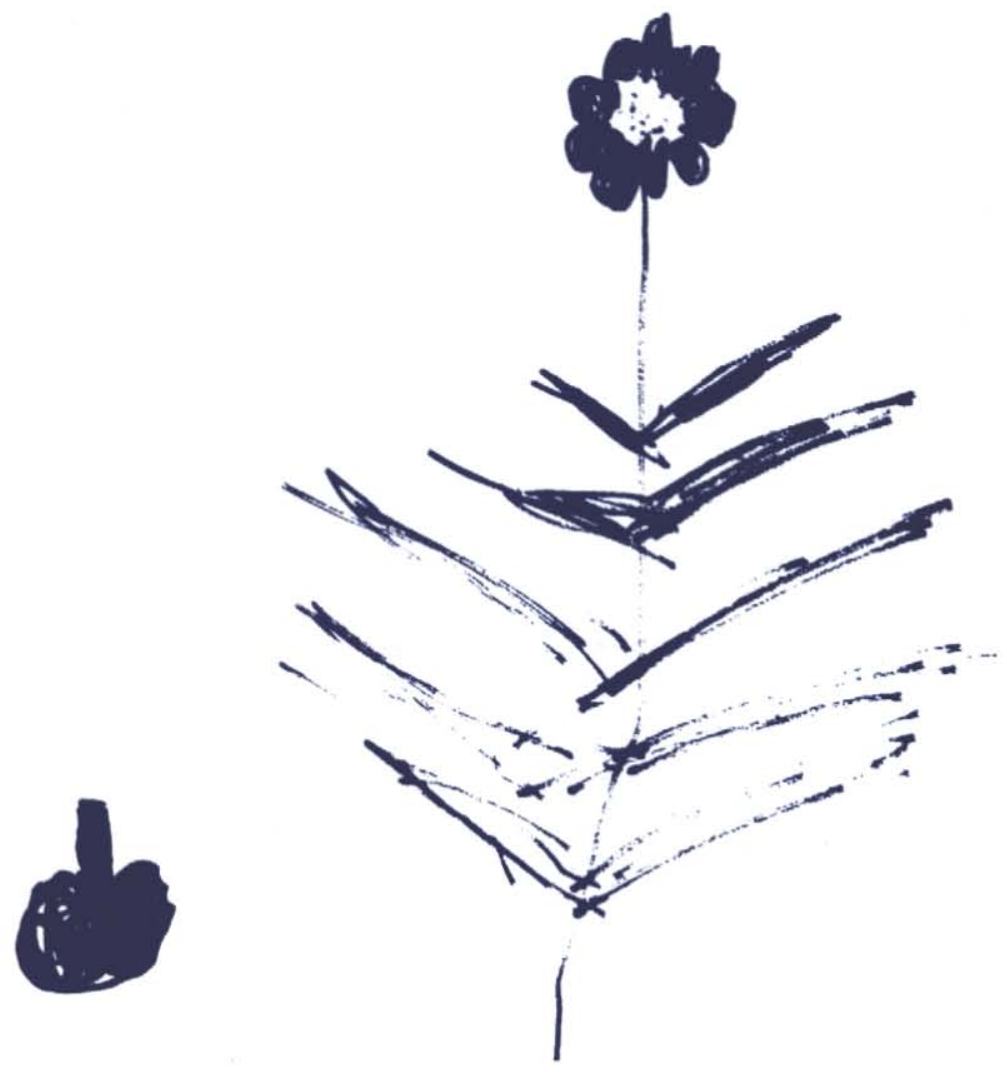


12.

trois quatre cinq

cinq chandelles à vue d'oeil

allumées soufflées

(I'enfance de l'art)

belles années de pousse

remplies de gestes nouveaux

et de promesses quelque part

trente-six chandelles brûlant

les deux bouts de l'âge

la vie débordant les yeux

et la bouche pleine de gâteau 